\title{
Aplicabilidade da Legislação Ambiental em um Posto de Combustíveis em Juazeiro do Norte/Ceará
}

\author{
Fernanda Fernandes de Sousa Lima ${ }^{1}$; Maria Cristina Delmondes Nascimento ${ }^{2}$; Athena de Albuquerque Farias ${ }^{3}$
}

Resumo: O presente trabalho objetivou, através de pesquisa de campo, com observação in loco, verificar o condicionamento e destinação final dos resíduos sólidos gerados, bem como verificar a adequação da estrutura física em relação a resolução CONAMA 273/00, em um posto de combustíveis em juazeiro do Norte, estado do ceará. Também buscou verificar se o posto de combustíveis possui processo de Licenciamento Ambiental junto a Superintendência Estadual do Meio Ambiente do Ceará. Os resultados levaram a constatação de que o mesmo possui: tubulações exaladoras de gases com válvula anti-chama, o piso da área do abastecimento e dá área de descarga é feito em concreto armado com canaletas interligadas a Caixa separadora de água e óleo, O armazenamento do combustível é feito através de 03 (três) tanques jaquetados. O referido posto possui Licença Ambiental vigente, emitida pelo órgão ambiental estadual. O licenciamento ambiental é sem dúvida um processo de grande importância no âmbito da preservação do meio ambiente, pois através dele pode-se fiscalizar e exigir de empreendimentos com potencial de degradação formas de minimizar os impactos ambientais negativos causados por suas atividades. Com base no exposto pode-se concluir que o desempenho ambiental do posto analisado encontra-se satisfatório quanto aos requisitos ambientais legais analisados.

Palavras-chave: Posto de Combustível, Resíduos Sólidos, Licenciamento Ambiental.

\section{Applicability of Environmental Legislation to a Fuel Station in Juazeiro do Norte - Ceará}

The present work aimed, through field research, with in situ observation, to verify the conditioning and final destination of the solid wastes generated, as well as to verify the adequacy of the physical structure in relation to the resolution CONAMA 273/00, in a fuel station in Juazeiro do norte, state of ceará. Also sought to verify if the fuel station has an Environmental Licensing process with the State Superintendence of the Environment of Ceará. The results showed that it has: gas exhalation pipes with anti-flame valve, the floor of the area of the supply and gives discharge area is made of reinforced concrete with interconnected channels the water and oil separator box, storage Of the fuel is made through 03 (three) jacked tanks. The said site has a valid Environmental License, issued by the state environmental agency. Environmental licensing is undoubtedly a process of great importance in the preservation of the environment, since through it it is possible to control and demand from enterprises with potential degradation ways to minimize the negative environmental impacts caused by their activities. Based on the above, it can be concluded that the environmental performance of the station analyzed is satisfactory in relation to the legal environmental requirements analyzed.

Keywords: Fuel Station, Solid Waste, Environmental Licensing.

\footnotetext{
1 Graduação em Biologia pela Universidade Regional do cariri - URCA. Especialização em Gestão Ambiental pela faculdade Vale do Jaguaribe, Ceará. Contato: fernanda.fernandes@semace.ce.gov.br;

${ }^{2}$ Doutoranda em Educação pela Universidade Hispano Guarani - PY; Mestre em Ciências da Educação; Especialização em Politicas Públicas e Docência do Ensino Superior pela Faculdade de Formação de Professores de Araripina - FAFOPA; Especialização em Educação Ambiental - FAFOPA; Possui graduação em Ciências Biológicas pela Universidade Federal do Vale do São Francisco; Graduação em Licenciatura em Pedagogia pela Faculdade Evangélica do Piauí (2012) Graduação em Engenharia Agronomica pela Faculdade de Ciências Agrárias De Araripna; Coordenadora Pedagógica; Professor do departamento pedagógico do Instituto Educacional Ruymar Gomes, professora da Escola Dionisio Bom de Oliveira. Contato: Cristina_delmondes@hotmail.com

${ }^{3}$ Advogada pela Faculdade dos Guararapes - PE. Especialista em Direito Processual do Trabalho pela Faculdades Integradas de Cruzeiro - SP. Contato: athena.farias@gmail.com.
} 


\section{Introdução}

Este trabalho foi realizado com base na realidade de um posto de combustíveis localizados na cidade de Juazeiro do Norte, no estado do Ceará. Estes estabelecimentos comerciais são considerados potencialmente ou parcialmente poluidores e geradores de acidentes ambientais, conforme a Resolução CONAMA 273 de 29 de novembro de 2000, O posto foi escolhido aleatoriamente com o intuito de verificar a aplicabilidade da Legislação Ambiental quanto ao acondicionamento e destinação final dos resíduos sólidos gerados nos postos de abastecimento de combustível.

Devido ao crescimento demográfico e ao consumismo exagerado da população há um aumento na produção de resíduos, fazendo com que venha ocorrer dificuldades na conservação ambiental. A atividade de revenda de combustíveis gera resíduos capazes de impactar significativamente o ambiente natural, faze-se necessário conhecer estes resíduos e, a luz da legislação, destiná-los de forma adequada.

Para atender a demanda dos clientes, nos últimos anos os postos revendedores vêm deixando de ser apenas um local que exerça a atividade de revenda varejista de combustíveis líquidos derivados de petróleo, agregando outros valores á seu espaço físico e dispondo de serviços tais como: lavagem de veículos, alinhamento, troca de óleo, borracharias, loja de conveniência, lanchonetes, locadoras entre outras.

Os principais resíduos gerados por esses serviços consistem em: estopas contaminadas, óleo lubrificante contaminado, embalagens de óleo, emissão de produtos químicos, filtro usado, pneus inservíveis, efluentes líquidos e areia resultante da caixa separadora de água e óleo.

De acordo com dados do IBGE e ABRELPE(2012) o Brasil gerou somente de resíduos sólidos urbanos 62.730 .096 milhões de toneladas, esse dado revela um aumento de 1,3\% na geração em relação a 2011, crescimento que se repete a cada ano. Ainda segundo a ABRELPE apenas 57,98\% dos resíduos recebem destinação adequada, ou seja, são levados a aterros sanitários, reciclados ou coprocessado, o restante, cerca de 42,02\% são levados a lixões ou jogados nas ruas.

A crescente preocupação ambiental que contamina de forma positiva a humanidade deve-se, em grande parte, pelo modelo de desenvolvimento adotado no último século. As empresas, não isentas desta preocupação, vem buscando modelos de gestão para melhorar sua 
relação com o meio ambiente. Ao mesmo tempo os consumidores passam a cobrar das organizações a criação de mecanismos para um consumo consciente e sustentável.

Atuar de forma ambientalmente responsável e sustentável é um diferencial entre empresas que querem se destacar no mercado cada vez mais competitivo. Quanto mais rápido essa percepção é internalizada pela empresa, maior será a chance de permanecer no mercado, onde o consumo aliado ao compromisso com o meio ambiente torna-se imperativo.

De acordo com Philippi (2000), as empresas são influenciadas por diversos fatores que a induzem a ter posturas ambientalmente responsáveis, dentre elas está a percepção das vantagens em termos competitivos, a melhoria da imagem ante a sociedade e a redução de custos na produção, alcançados com a adoção de programas de gestão específicos, buscando a solução de problemas oriundos dos impactos ambientais desses processos, incluindo a racionalização no consumo dos insumos e redução dos resíduos gerados.

$\mathrm{O}$ crescimento de vários problemas ambientais ligados aos postos de abastecimento levou a tê-las como objeto principal deste estudo. Dentre estes problemas destaca-se a geração de resíduos em quantidade significativa. Desta forma, o diagnóstico dos resíduos se reveste de importância para evitar as consequências nocivas ao homem e ao meio ambiente quando este não é destinado corretamente.

A classificação dos resíduos é importante para definir a melhor estratégia de gerenciálo. As classificações se baseiam em determinadas características e propriedades identificadas nos resíduos. Estes são classificados basicamente segundo sua origem e grau de periculosidade. O conhecimento da origem dos resíduos é fundamental para determinar a quem compete a responsabilidade pelo seu gerenciamento.

A NBR 10.004 procura classificar os resíduos sólidos quanto aos riscos potenciais ao meio ambiente e à saúde pública, o objetivo desta classificação é gerenciar de forma adequada os resíduos.

O objetivo foi verificar a aplicabilidade da Legislação Ambiental quanto ao acondicionamento e destinação final dos resíduos sólidos gerados em um posto de abastecimento de combustível no município de Juazeiro do Norte/CE, bem como verificar a adequação da estrutura física em relação a resolução CONAMA 273/00, e Verificar se o posto de combustíveis possui processo de Licenciamento Ambiental junto a Superintendência Estadual do Meio Ambiente do Ceará. 


\section{Resíduos Sólidos}

Resíduos sólidos podem ser definidos, segundo a NBR 10004/1987, como resíduos no estado sólido ou semissólido, que resultam de atividade da comunidade, de origem: industrial, doméstica, hospitalar, comercial, agrícola, de serviços e de varrição. Considera-se também resíduos sólidos os lodos provenientes do sistema de tratamento de água, aqueles gerados em equipamentos e instalações de controle de poluição, bem como determinados líquidos, cujas peculiaridades tornem inviável o seu lançamento na rede pública de esgoto ou corpo d'água, ou exijam para isso soluções técnicas e economicamente inviáveis em face da melhor técnica disponível.

A Resolução CONAMA N 5 de 5 de agosto de 1993 classifica os resíduos em grupos:

GRUPO A: resíduos que apresentam risco potencial à saúde pública e ao meio devido a presença de agentes biológicos.

Neste grupo estão incluídos sangue e hemoderivados; animais usados como cobaias em laboratório, bem como materiais que entrarão em contato com estes; excreções e líquidos orgânicos; meios de cultura; tecidos, órgãos e peças anatômicas; filtros de gases aspirados de área contaminada; resíduos de áreas de isolamento; resíduos de laboratório de análise clinicas e de atendimento ambulatorial; resíduos de sanitários de unidade de internação e de enfermaria. Inclui-se também objetos perfurantes ou cortantes, capazes de causar punctura ou corte, tais como lâminas de barbear, bisturi, agulhas, escalpes, vidros quebrados, etc, provenientes de prestadoras de serviço de saúde.

GRUPO B: resíduos que apresentam risco potencial à saúde pública e ao meio ambiente devido às suas características químicas. Enquadram-se neste grupo, dentre outros: drogas quimioterápicas e produtos contaminados por elas; resíduos farmacêuticos (medicamentos vencidos, contaminados, interditados ou não utilizados e demais produtos considerados perigosos conforme classificação da NBR 10.004 da Associação Brasileira de Normas Técnicas $-\mathrm{ABNT}$.

GRUPO C: rejeitos radioativos, tais como materiais radioativos ou contaminados com radionuclídeos, provenientes de laboratórios de análises clínicas, serviços de medicina nuclear e radioterapia, segundo Resolução CNEN 6.05. 
GRUPO D: são os resíduos comuns que não se enquadram nos grupos anteriormente descritos.

A classificação dos resíduos é importante para definir a melhor estratégia de gerenciálo. As classificações se baseiam em determinadas características e propriedades identificadas nos resíduos. Estes são classificados basicamente segundo sua origem e grau de periculosidade. O conhecimento da origem dos resíduos é fundamental para determinar a quem compete a responsabilidade pelo seu gerenciamento.

A NBR 10.004 procura classificar os resíduos sólidos quanto aos riscos potenciais ao meio ambiente e à saúde pública, o objetivo desta classificação é gerenciar de forma adequada os resíduos.

De acordo com a NBR 10.004, os resíduos são classificados conforme o quadro 1:

Quadro 1: Classificação dos resíduos

\begin{tabular}{|l|l|}
\hline $1-$ Resíduos Classe I & - Perigosos \\
\hline $2-$ Resíduo Classe II & - Não perigosos \\
\hline - Resíduo classe IIA & - Não inertes \\
\hline - Resíduo classe IIB & - Inertes \\
\hline
\end{tabular}

\section{Resíduos classe I - Perigosos}

São aqueles que apresentam periculosidade, característica apresentada por um resíduo que em função de suas propriedades físicas, químicas ou infectocontagiosas pode apresentar risco à saúde pública, provocando mortalidade, incidência de doenças ou acentuando seus índices, ou ainda riscos ao meio ambiente, quando o resíduo for gerenciado de forma inadequada.

\section{Inflamabilidade}

Um resíduo é caracterizado como inflamável quando uma amostra representativa dele, obtida conforme preconiza a NBR 10.004, apresentar qualquer uma das seguintes propriedades: 
a) ser líquida e ter ponto de fulgor inferior a $60^{\circ} \mathrm{C}$, determinado conforme ABNT NBR 14.598 ou equivalente, excetuando-se as soluções aquosas com menos de $24 \%$ de álcool em volume;

b) Não ser líquida e ser capaz de, sob condições de temperatura e pressão de $25^{\circ} \mathrm{C}$ e 0,1 Mpa(1ATM), produção fogo por fricção, absorção de umidade ou alterações químicas espontâneas e, quando inflamada, queimar vigorosa e persistentemente, dificultando a extinção do fogo;

c) ser um oxidante definido como substância que pode liberar oxigênio e, como resultado, estimular a combustão e aumentar a intensidade do fogo em outro material;

d) ser um gás comprimido inflamável, conforme a Legislação Federal sob transporte de produtos perigosos (Portaria n ${ }^{\circ}$ 204/1997 do Ministério dos Transportes).

Corrosividade

Um resíduo é caracterizado como corrosivo se uma amostra representativa dele, obtida segunda ABNT NBR 10.007, apresentar uma das seguintes propriedades:

a) ser aquosa e apresentar $\mathrm{pH}$ inferior ou igual a 2, ou, superior ou igual a 12,5 , ou sua mistura com água, na proporção de 1:1 em peso, produzir uma solução que apresente pH inferior a 2 ou igual a 12,5 ;

b) ser líquida ou, quando misturada em peso equivalente de água, produzir um líquido e corroer o aço (COPANT 1020) a uma razão maior que $6,35 \mathrm{~mm}$ ao ano, a uma temperatura de $55^{\circ} \mathrm{C}$, de acordo com USEPA SW 846 ou equivalente.

\section{Reatividade}

Um resíduo é caracterizado como reativo se uma amostra representativa dele, obtida pela NBR 10.007 e apresentar uma das seguintes características:

a) Ser normalmente instável e reagir de forma violenta e imediata, sem detonar;

b) reagir violentamente com a água;

c) Formar misturas potencialmente explosivas com a água;

d) gerar gases, vapores e fumos tóxicos em quantidades suficientes para provocar danos à saúde pública ou ao meio ambiente, quando misturados com água; 
e) Possuir em sua constituição os íons CNOU S2- em concentrações que ultrapassem os limites de 250mg de HCN liberável por quilograma de resíduo ou 500mg de H2S liberável por quilograma de resíduo, de acordo com ensaio estabelecido no USEPA SW 846;

f) ser capaz de produzir reação explosiva ou detonante sob a ação de forte estímulo, ação catalítica ou temperatura em ambientes confinados;

g) ser capaz de produzir, prontamente, reação ou decomposição detonante ou explosiva a $25^{\circ} \mathrm{C}$ e $0,1 \mathrm{Mpa}(1 \mathrm{ATM})$;

h) ser explosivo, definido como uma substância fabricada para produzir um resultado prático, através de explosão ou efeito pirotécnico, esteja ou não substância contida em dispositivo preparado para este fim.

\section{Toxidade}

Um resíduo é caracterizado como tóxico se uma amostra representativa dele, de acordo com a NBR 10.007, apresentar uma das seguintes propriedades:

a) quando o extrato obtido desta amostra, segundo NBR 10.005, contiver qualquer um dos contaminantes em concentrações, o resíduo deve ser caracterizado como tóxico com base no ensaio de lixiviação;

b) possuir uma ou mais substâncias constantes e apresentar toxidade. Para avaliação dessa toxidade, devem ser considerados os seguintes fatores:

- natureza do constituinte no resíduo;

- potencial que o constituinte, ou qualquer produto tóxico de sua degradação, tem para migrar do resíduo para o ambiente, sob condições impróprias de manuseio;

- persistência do constituinte ou qualquer produto tóxico de sua degradação;

- potencial que o constituinte, ou qualquer produto tóxico de sua degradação, tem para degradar-se em constituintes não perigosos, considerando a velocidade em que ocorre a degradação;

- extensão em que o constituinte, ou qualquer produto tóxico de sua degradação é capaz de bioacumulação nos ecossistemas;

- efeito nocivo pela presença de agente teratogênico, mutagênico, carcinogênico ou eco tóxico, associados a substâncias isoladamente ou decorrente do sinergismo entre as substâncias constituintes do resíduo; 
c) ser constituída por restos de embalagens contaminadas com substâncias;

d) resultar de derramamentos ou de produtos fora de especificação ou do prazo de validade que contenham qualquer substância;

e) ser comprovadamente letal ao ser humano;

f) possuir substância em concentração comprovadamente letal ao ser humano ou estudos do resíduo que demonstrem um DS50 oral para ratos menor que $50 \mathrm{mg} / \mathrm{Kg}$ ou CL50 inalação para ratos menor que $2 \mathrm{mg} / \mathrm{L}$ ou uma DL50 dérmica para coelhos menor que $200 \mathrm{mg} / \mathrm{Kg}$. Patogenicidade

Um resíduo é caracterizado como patogênico se uma amostra representativa dele, obtida de acordo com a NBR 10.007, contiver ou se houver suspeita de conter, microrganismos patogênicos, proteínas virais, ácido desoxirribonucleico (ADN) recombinantes, organismos geneticamente modificados, plasmódios, cloroplastos, mitocôndrias ou toxinas capazes de produzir doenças em homens, animais e vegetais.

\section{Resíduos Classe II - Não perigosos}

\section{Classe II A - Não inertes}

Aqueles que não se enquadram nas classificações de resíduo classe I - perigosos ou de resíduo classe II A - não inertes, podem ter propriedades como: biodegradabilidade, combustibilidade ou solubilidade em água.

\section{Classe II B - Inertes}

Quaisquer resíduos que, quando expostos de uma forma representativa, segundo a NBR 10.007, e submetidos a um contato dinâmico e estático com água destilada ou desionizada, à temperatura ambiente, conforme NBR 10.006, não tiveram nenhum de seus constituintes solubilizados e concentrações superiores aos padrões de potabilidade de água, excetuando-se aspecto, cor, turbidez, dureza e sabor. 


\section{Resíduos gerados nos postos de abastecimento}

Os principais resíduos gerados por esses serviços consistem em: pneus inservíveis, óleo lubrificante contaminado - OLUC, embalagens de OLUC, filtro usado, estopas contaminadas, emissão de produtos químicos, efluentes líquidos, areia resultante da caixa separadora de água e óleo, papel, plástico e lâmpadas fluorescentes.

Segundo Santos, (2005), os impactos ambientais causados por esses resíduos provenientes da atividade de posto de combustível podem ser controlados e/ou evitados, desde que, se invista em equipamentos mais adequados, implementando novas tecnologias menos impactantes, para controle ambiental, promovendo um melhor desempenho ambiental.

O descarte inadequado dos resíduos sólidos pode causar danos ambientais irreparáveis. Como afirma GUIDONI (2005) os aterros sanitários não podem receber estes resíduos visto que a contaminação do solo seria imediata. A alternativa para tratamento desses resíduos seria a reciclagem e a incineração.

Os pneus são constituídos por uma estrutura complexa, sendo composto por diversos tipos de materiais, como: borracha, tecido de náilon ou poliéster, aço. Esses componentes conferem as características necessárias ao seu desempenho e segurança. No momento os pneus são descartados ou destinados à reciclagem. (Manual Coleta Seletiva, 2003).

Segundo a Resolução CONAMA N 258 no art. $1^{\circ}$ as empresas que fabricam e as importadoras de pneumáticos são obrigadas a coletar e dar a destinação final adequada aos pneus inservíveis existentes no território nacional, na proporção definida na Resolução relativamente às quantidades fabricadas e/ou importadas.

Os óleos lubrificantes automotivos são substâncias utilizadas para lubrificar, refrigerar, limpar e manter limpo o motor, proteger o motor contra corrosão, desgaste e formação de ácidos no seu interior, auxiliar na vedação da câmara de combustão, aumentando a vido útil do motor (PROGRAMA..., 2007). É um produto composto de óleos básicos, hidrocarbonetos saturados e aromáticos, e representa cerca de $2 \%$ dos derivados de petróleo, recurso natural nãorenovável, ou seja, é um recurso que pode se esgotar. O uso automotivo representa atualmente $60 \%$ do consumo nacional, principalmente em motores à diesel. Também são usados em sistemas hidráulicos, motores estacionários, turbinas e ferramentas de corte. (RMAI ONLINE, 2012). 
Quando utilizados, os óleos lubrificantes se contaminam com produtos orgânicos de oxidação e outros materiais, resultado do desgaste dos metais e outros sólidos, reduzindo sua quantidade. Quando a quantidade desses contaminantes é excessiva, o lubrificante perde sua capacidade e deve ser substituído, passando a ser classificado como óleo lubrificante usado OLUC, e normalmente é utilizado para outras aplicações não previstas no ordenamento legal brasileiro: queimado em substituição ao óleo combustível, na lubrificação de correntes de motosserra, descartado diretamente na rede pública de esgoto ou na rede de drenagem pluvial, em corpos hídricos ou no solo. Embora proibida no Brasil, à queima é uma forma comum de desvio de óleos lubrificantes usados, coletadas por empresas não licenciadas (MINISTÉRIO DO MEIO AMBIENTE, 2007).

Os lubrificantes usados possuem diferentes tipos de contaminante, dependendo de sua origem, tais como: produto de oxidação (borras, gomas, lascas e vernizes), metais de desgaste (ferro, cobre, alumínio, estanho, etc.), metais componentes dos aditivos (zinco, fósforo, cloro, chumbo, enxofre, etc.), água, hidrocarbonetos leves (provenientes de combustíveis queimados), ácidos formados na combustão, sílica (poeira), etc. (TRISTÃO, J. A. M.; E.; VIÉGAS, R, F., 2008).

A ABNT citada anteriormente classifica o óleo lubrificante sado como resíduo perigoso (classe I) por apresentar toxidade.

Os óleos lubrificantes usados podem ser reutilizados quando encaminhados ao rerrefino, gerando óleos básicos para novas formulações. O rerrefino revela-se como o meio mais adequado para absorver a quantidade de óleo usado que é gerado no país através das atividades econômicas (RMAI ONLINE 2012).

As embalagens de OLUC contêm três tipos diferentes de plástico: Polietileno de Alta Densidade (PEAD), polipropileno (PP) e Polietileno de Baixa Densidade (PEBD). Estas embalagens estão contaminadas com óleos que dificultam o processo de reciclagem e exige uma etapa de separação da água do óleo. O Brasil gera 730 milhões de embalagens de óleo lubrificante por ano, sendo $60 \%$ de óleos automotivos e $40 \%$ industriais.

As estopas são utilizadas na limpeza de peças dos funcionários que manipulam resíduos como óleos. A disposição desses resíduos deve ser em Aterro sanitários ou incineração, outra alternativa é encaminhá-los ao reaproveitamento, devido ao seu poder calorífico em substituição aos combustíveis fósseis, após licenciamento pelo órgão ambiental competente. 
O termo plástico engloba uma série de tipos de resinas atualmente em uso no mercado. Entre estes podem ser citados: o PET (Tereftalato de Polietileno), o PEAD (Polietileno de alta densidade), o PVC (Cloreto de Polivinila), o PEBD (Polietileno de baixa densidade), O PP (Polipropileno), o OS (Poliestireno) e outras (utilizadas em plásticos especiais na engenharia, em CDs e DVDs, computadores etc.). A destinação correta desses materiais é a reciclagem por indústrias de artefatos plásticos ou terceiros prestadores de serviços. (MANUAL DE COLETA SELETIVA, 2003).

O papel é o nome genérico dado a uma variedade de produtos usados em escritórios, incluídos papéis de correspondências, bloco de anotações, copiadoras, impressoras, revistas e folhetos. A qualidade é medida pelas características de suas fibras. Papéis de correspondências e de copiadoras são normalmente brancos, mas podem ter várias cores. $\mathrm{O}$ descarte é formado por diferentes tipos de papéis, forçando os programas de reciclagem a priorizar algumas categorias mais valiosas, como o papel branco. A destinação ocorre para indústrias que reciclam o papel. (MANUAL DE COLETA SELETIVA, 2003).

As lâmpadas fluorescentes compactas ou tubulares contém mercúrio, substância tóxica nociva ao ser humano e ao meio ambiente. Quando intactas as lâmpadas não oferecem perigo algum ao homem ou ao meio ambiente, porém quando quebradas liberal mercúrio em forma de vapor, que, ao ser inalado pode se depositar no organismo.

A Organização Mundial da Saúde (OMS) estima em 33 miligramas de mercúrio por grama de creatinina urinária o limite de tolerância biológica para o ser humano. $\mathrm{O}$ descarte sistemático das lâmpadas em aterros, sem que haja sua descontaminação e sem os cuidados em seu armazenamento, eleve para níveis preocupantes a quantidade desse elemento químico no meio ambiente. Esse resíduo deve ser destinado para recuperação e descontaminação em empresas especializadas. (MANUAL DE COLETA SELETIVA, 2003).

\section{Legislação Ambiental}

De acordo com resolução CONAMA n ${ }^{\circ} 1$ de 1986 considera-se impacto ambiental qualquer alteração das propriedades físicas, químicas e biológicas do meio ambiente, causada por qualquer forma de matéria ou energia resultante das atividades humanas que, direta ou 
indiretamente, afetam: a saúde, a segurança e o bem-estar da população; as atividades sociais e econômicas; a biota; as condições estéticas e sanitárias do meio ambiente; e a qualidade dos recursos ambientais.

Dois passos foram essenciais para o surgimento do licenciamento ambiental, que levou certo tempo para se consolidar e começar a surtir o efeito desejado. O primeiro foi o capítulo exclusivo ao meio ambiente na Constituição Federal. O segundo foi o Decreto n ${ }^{\circ}$ 99.274/1990, que regulamentou a Lei Federal $n^{\circ}$ 6.938/1981, determinando definitivamente a obrigatoriedade do licenciamento ambiental (Solano, 2009).

Desde a Lei Federal n 6.938/81, regulamentada pelo Decreto Federal n. ${ }^{\circ}$ 99.274/90, a atividade de comércio varejista de combustíveis está submetida à legislação ambiental, sendo citada, também, como atividade sujeita ao licenciamento ambiental pela Resolução do Conselho Nacional do Meio Ambiente - CONAMA n 237/97 e mais recentemente pela resolução CONAMA $n^{\circ}$ 273/2000, que trata especificamente da padronização e licenciamento das atividades que possuem reservatórios e armazenamento de combustíveis, constituindo a mais abrangente e mais importante legislação referente à atividade.

Fica determinado pela Resolução do CONAMA n ${ }^{\circ} 273 / 2000$, em seu art. $1^{\circ}$ que todas as atividades referentes o setor de armazenamento e distribuição de combustíveis, deverão ser realizadas em conformidade com as normas técnicas expedidas pela $\mathrm{ABNT}$ ou pelo órgão ambiental competente.

Ainda com Base na Resolução acima, denomina e clássica esses empreendimentos da seguinte forma:

1. Posto Revendedor - PR: Instalação onde se exerça a atividade de revenda varejista de combustíveis líquidos derivados de petróleo, álcool combustível e outros combustíveis automotivos, dispondo de equipamentos e sistemas para armazenamento de combustíveis automotivos e equipamentos medidores;

2. Posto de Abastecimento - PA: Instalação que possua equipamentos e sistemas para o armazenamento de combustível automotivo, com registrador de volume apropriado para o abastecimento de equipamentos móveis, veículos automotores terrestres, aeronaves, embarcações ou locomotivas; e cujos produtos sejam destinados exclusivamente ao uso do detentor das instalações ou de grupos 
fechados de pessoas físicas ou jurídicas, previamente identificadas e associadas em formas de empresas, cooperativas, condomínios, clubes ou assemelhados;

3. Instalação de Sistema Retalhista - ISR: Instalação com sistema de tanques para o armazenamento de óleo diesel, óleo combustível, querosene iluminante, destinada a exercício da atividade de Transportador Revendedor Retalhista;

4. Posto Flutuante - PF: Toda embarcação sem propulsão empregada para o armazenamento, distribuição e comércio de combustíveis que opera em local fixo e determinado;

Com efeito, a Lei 9.605/98 (Lei de Crimes Ambientais) retrata na Seção III (Da Poluição e outros Crimes Ambientais): Art. 54: Causar Poluição de qualquer natureza em níveis tais que resultem ou possam resultar em danos a saúde humana, ou que provoquem a mortandade de animais ou a destruição significativa da flora: Pena Reclusão, de 1 (um) a 4 (quatro) anos, e multa.

Os riscos ambientais constituem uma nova preocupação que deve estar presente nas decisões dos empresários e nos programas de imagem institucional das empresas (VALLE, 2000).

Entende-se que os aspectos ambientais decorrentes das atividades geradas pelos postos de abastecimento ocasionam impacto ambiental de forma direta ou indiretamente no meio físico, biológico e social.

\section{Do Licenciamento Ambiental}

De acordo com resolução CONAMA nº 1 de 1986 considera-se impacto ambiental qualquer alteração das propriedades físicas, químicas e biológicas do meio ambiente, causada por qualquer forma de matéria ou energia resultante das atividades humanas que, direta ou indiretamente, afetam: a saúde, a segurança e o bem-estar da população; as atividades sociais e econômicas; a biota; as condições estéticas e sanitárias do meio ambiente; e a qualidade dos recursos ambientais.

Dois passos foram essenciais para o surgimento do licenciamento ambiental, que levou certo tempo para se consolidar e começar a surtir o efeito desejado. O primeiro foi o capítulo 
exclusivo ao meio ambiente na Constituição Federal. O segundo foi o Decreto n ${ }^{\circ}$ 99.274/1990, que regulamentou a Lei Federal $n^{\circ} 6.938 / 1981$, determinando definitivamente a obrigatoriedade do licenciamento ambiental (Solano, 2009).

Desde a Lei Federal nº 6.938/81, regulamentada pelo Decreto Federal n. ${ }^{\circ}$ 99.274/90, a atividade de comércio varejista de combustíveis está submetida à legislação ambiental, sendo citada, também, como atividade sujeita ao licenciamento ambiental pela Resolução do Conselho Nacional do Meio Ambiente - CONAMA n 237/97 e mais recentemente pela resolução CONAMA no 273/2000, que trata especificamente da padronização e licenciamento das atividades que possuem reservatórios e armazenamento de combustíveis, constituindo a mais abrangente e mais importante legislação referente à atividade.

Fica determinado pela Resolução do CONAMA n ${ }^{\circ} 273 / 2000$, em seu art. $1^{\circ}$ que todas as atividades referentes o setor de armazenamento e distribuição de combustíveis, deverão ser realizadas em conformidade com as normas técnicas expedidas pela $\mathrm{ABNT}$ ou pelo órgão ambiental competente.

Ainda com Base na Resolução acima, denomina e clássica esses empreendimentos da seguinte forma:

- Posto Revendedor - PR: Instalação onde se exerça a atividade de revenda varejista de combustíveis líquidos derivados de petróleo, álcool combustível e outros combustíveis automotivos, dispondo de equipamentos e sistemas para armazenamento de combustíveis automotivos e equipamentos medidores;

- Posto de Abastecimento - PA: Instalação que possua equipamentos e sistemas para o armazenamento de combustível automotivo, com registrador de volume apropriado para o abastecimento de equipamentos móveis, veículos automotores terrestres, aeronaves, embarcações ou locomotivas; e cujos produtos sejam destinados exclusivamente ao uso do detentor das instalações ou de grupos fechados de pessoas físicas ou jurídicas, previamente identificadas e associadas em formas de empresas, cooperativas, condomínios, clubes ou assemelhados;

- Instalação de Sistema Retalhista - ISR: Instalação com sistema de tanques para o armazenamento de óleo diesel, óleo combustível, querosene iluminante, destinada a exercício da atividade de Transportador Revendedor Retalhista; 
- Posto Flutuante - PF: Toda embarcação sem propulsão empregada para o armazenamento, distribuição e comércio de combustíveis que opera em local fixo e determinado;

Com efeito, a Lei 9.605/98 (Lei de Crimes Ambientais) retrata na Seção III (Da Poluição e outros Crimes Ambientais): Art. 54: Causar Poluição de qualquer natureza em níveis tais que resultem ou possam resultar em danos a saúde humana, ou que provoquem a mortandade de animais ou a destruição significativa da flora: Pena Reclusão, de 1 (um) a 4 (quatro) anos, e multa.

Entende-se que os aspectos ambientais decorrentes das atividades geradas pelos postos de abastecimento ocasionam impacto ambiental de forma direta ou indiretamente no meio físico, biológico e social.

Apresentam-se abaixo as condições de licenciamento de acordo com o art. $1^{\circ}$ da Resolução CONAMA no 237 de 1997:

I - Licenciamento Ambiental: procedimento administrativo pelo qual o órgão ambiental competente licencia a localização, instalação, ampliação e a operação de empreendimentos e atividades utilizadoras de recursos ambientais, consideradas efetiva ou potencialmente poluidoras ou daquelas que, sob qualquer forma, possam causar degradação ambiental, considerando as disposições legais e regulamentares e as normas técnicas aplicáveis ao caso.

II - Licença Ambiental: ato administrativo pelo qual o órgão ambiental competente, estabelece as condições, restrições e medidas de controle ambiental de que deverão ser obedecidas pelo empreendedor, pessoa física ou jurídica, para localizar, instalar, ampliar e operar empreendimentos ou atividades utilizadoras dos recursos ambientais consideradas efetiva ou potencialmente poluidoras ou aquelas que, sob qualquer forma, possam causar degradação ambiental.

III - Estudos Ambientais: são todos e quaisquer estudos relativos aos aspectos ambientais relacionados à localização, instalação, operação e ampliação de uma atividade ou empreendimento, apresentado como subsídio para a análise da licença requerida, tais como: relatório ambiental, plano e projeto de controle ambiental, relatório ambiental preliminar, diagnóstico ambiental, plano de manejo, plano de recuperação de área degradada e análise preliminar de risco. 
IV - Impacto Ambiental Regional: é todo e qualquer impacto ambiental que afete diretamente (área de influência direta do projeto), no todo ou em parte, o território de dois ou mais Estados.

No art. $8^{\circ}$ desta Resolução CONAMA compete ao Poder Público, no exercício de sua competência de controle, expedir as seguintes licenças:

I - Licença Prévia (LP) - concedida na fase preliminar do planejamento do empreendimento ou atividade aprovando sua localização e concepção, atestando a viabilidade ambiental e estabelecendo os requisitos básicos e condicionantes a serem atendidos nas próximas fases de sua implementação;

II - Licença de Instalação (LI) - autoriza a instalação do empreendimento ou atividade de acordo com as especificações constantes dos planos, programas e projetos aprovados, incluindo as medidas de controle ambiental e demais condicionantes, da qual constituem motivo determinante;

III - Licença de Operação (LO) - autoriza a operação da atividade ou empreendimento, após a verificação do efetivo cumprimento do que consta das licenças anteriores, com as medidas de controle ambiental e condicionantes determinados para a operação.

O órgão ambiental competente deve estabelecer os prazos de validade de cada tipo de licença. Para a Licença Prévia e a Licença de Instalação, o prazo de validade deve ser, no mínimo, o estabelecido pelo cronograma de elaboração dos projetos e de instalação, respectivamente, não podendo ser superior a 5 (cinco) anos, no caso da LP, e a 6 (seis) anos, no caso da LI. Já para a Licença de Operação, o prazo de validade deve considerar os planos de controle ambiental e ser de, no mínimo, 4 (quatro) anos e, no máximo, 10 (dez) anos (CONAMA, 1997).

As normas e critérios para o licenciamento ambiental são estabelecidos pelo CONAMA, mediante proposta do IBAMA. Os Estados, na esfera e áreas de suas competências, devem elaborar normas supletivas e complementares e padrões relacionados com o meio ambiente, observados os que forem estabelecidos pelo CONAMA, não podendo ser menos restritivos. Os municípios, por sua vez, também podem elaborar normas, observados os padrões estabelecidos a nível federal e estadual, apresentando os mesmos limites ou de maior restrição (BRASIL, 1981). 
É de competência do Instituto Brasileiro do Meio Ambiente e dos Recursos Naturais Renováveis - IBAMA, o licenciamento ambiental de atividades e obras cujos impactos ambientais diretos ultrapassem os limites territoriais do País ou de um ou mais Estados, estejam localizadas no mar territorial, na plataforma continental, na zona econômica exclusiva, em terras indígenas ou em unidades de conservação do domínio da União ou sejam destinadas a manipular material radioativo ou utilizar energia nuclear (CONAMA, 1997).

Compete ao órgão Estadual do Meio Ambiente, o licenciamento dos empreendimentos e atividades cujos impactos ambientais diretos ultrapassem os limites territoriais de um ou mais municípios, estejam localizados em mais de um município, em unidades de conservação de domínio estadual, em florestas e demais formas de vegetação natural de preservação permanente (CONAMA, 1997).

O licenciamento de empreendimentos e atividades, cujo impacto ambiental seja local compete ao órgão ambiental municipal, e mais aquelas que lhe forem delegadas pelo Estado por instrumento legal ou convênio (CONAMA, 1997).

\section{Licenciamento Ambiental junto a SEMACE}

A fim de instruir processo de licenciamento de posto combustível na Superintendência Estadual do Meio Ambiente, o interessado deve apresentar a seguinte documentação:

I- Croqui de localização do empreendimento: Indicando a situação do terreno em relação ao corpo receptor e cursos d'água e identificando o ponto de lançamento do efluente das águas domésticas e residuárias após tratamento, tipos de vegetação existente no local e seu entorno, bem como contemplando a caracterização das edificações existentes em um raio de $100 \mathrm{~m}$ com destaque para a existência de clínicas médicas, hospitais, sistema viário, habitações multifamiliares, escolas, indústrias ou estabelecimentos comerciais, conforme Resolução CONAMA $273 / 2000$.

II- Matrícula do imóvel ou Certidão expedida pelo Cartório expedida pelo Cartório de Registro de Imóveis; 
III- Cópia da Identificação de Pessoa Jurídica (CNPJ) atualizado e Cópia do Contrato Social;

IV-Anuência do Município;

V- Pagamento do custo do serviço;

VI-Autorização do DER ou DNIT;

VII- Planta Georreferenciada, que deverá ser apresentada uma via em meio impresso assinada e acompanhada da ART do responsável técnico;

VIII- Publicação em jornal da solicitação da Licença;

IX-Cadastro Técnico Federal - CTF Certificado de Regularidade no Cadastro Técnico Federal-CTF de atividade potencialmente poluidora e/ou utilizadora de recursos naturais emitido pelo IBAMA;

X- Plano de Emergência Plano de Emergência, conforme diretrizes constantes no Termo de Referência emitido pela SEMACE, acompanhado da taxa de análise do estudo e da ART do técnico responsável pela elaboração do mesmo;

XI-Certificado de Conformidade do Corpo de Bombeiros atualizado;

XII- Certificados emitidos pelo INMETRO e as notas fiscais dos tanques e dos equipamentos do Sistema de Abastecimento Subterrâneo de Combustíveis - SASC instalados no empreendimento;

XIII- Programa de treinamento de pessoal - operação, manutenção e resposta a incidentes: apresentar o certificado de conclusão do curso de capacitação dos trabalhadores, nos termos da NR-20, e documento que comprove a proficiência do instrutor responsável pelo treinamento.

Além desta documentação, os postos combustíveis passam a se adequar as seguintes exigências, estipuladas pela Lei Estadual No 12.621 de 26 de Agosto de 1996:

- O tanque deverá possuir, no mínimo, um acesso ao seu interior, tal que permita a inspeção por técnico especializado, sem que seja necessário qualquer serviço de corte em sua estrutura, atendendo a norma da ABNT;

- O tanque deverá estar protegido externamente por revestimento que não permita o ataque da corrosão ou por um sistema que inclui revestimento associado à proteção catódica, conforme as normas da ABNT; 
- A boca de recebimento de produto do tanque deve possuir adaptador de resgate rápido, para que o abastecimento só possa ser feito através do sistema tipo descarga selada, de modo que não seja possível o transbordamento durante o seu abastecimento;

- As tubulações ligadas ao tanque devem possuir proteção contra corrosão, idêntica ou compatível com a usada no tanque;

- A bomba de sucção deve possuir válvula de retenção junto a entrada de produto, alinhando-se sua utilização na extremidade da tubulação no interior do tanque, evitando-se assim, que, na falta de estanqueidade de tubo, ou produto vaze para o solo;

- Deverá haver poços de inspeção ou qualquer outro sistema de detecção de vazamentos, independentemente do Livro de Movimentação de Combustível LMC. A quantidade de poços de inspeção deve ser de tal forma dimensionada, que seja possível detectar um vazamento em qualquer tanque ou tubulação do sistema de abastecimento de combustível, num mínimo de 03 ;

- Possuir sistema de drenagem de águas contaminadas com combustíveis, óleos ou graxas, independente do uso da drenagem pluvial ou de águas servidas. Esse sistema deverá separar a água dos demais contaminantes referidos;

- Todos os postos de serviços deverão ser licenciados anualmente pela SEMACE, que inclusive autorizará ou não o seu funcionamento.

\section{O Sistema de Armazenamento Subterrâneo de Combustíveis - SASC e os Impactos Ambientais causados pelos Postos de distribuição de combustíveis}

Impacto Ambiental é qualquer alteração das propriedades físicas, químicas e biológicas do meio ambiente, causada por qualquer forma de matéria ou energia resultante das atividades humanas que, direta ou indiretamente, afetam: a saúde, a segurança e o bem-estar da população; as atividades sociais e econômicas; a biota; as condições estéticas e sanitárias do meio ambiente; a qualidade dos recursos ambientais (Resolução CONAMA n. 001, de 23 de janeiro de 1986, art. $1^{\circ}$.). 
Segundo Rocha 2004, os impactos ambientais devem ser classificados quanto aos aspectos: positivos e negativos; diretos e indiretos; imediatos e em longo prazo; temporários e permanentes; de grau de reversibilidade; de propriedades cumulativas e sinérgicas; da distribuição dos ônus e benefícios sociais; da definição das medidas mitigadoras dos impactos negativos e da elaboração do programa de acompanhamento e monitoramento dos impactos positivos e negativos, indicando os fatores e parâmetros a serem considerados.

O SASC é composto por complexo sistema de tubulações, conexões e tanques, interligados e enterrados. A ocorrência de vazamentos no SASC tem sido objeto de crescente preocupação, em função dos riscos associados a esses eventos, tanto para a segurança e saúde da população, como para o meio ambiente. Quando ocorre algum tipo de vazamento, transbordamentos ou derrames, o produto pode penetrar no solo e pode atingir os sistemas subterrâneos de esgoto, de drenagem de águas pluvial, cabos e caixas de distribuição de energia elétrica ou telefonia, poços artesianos e garagens, entre outros.

Os compostos Benzeno, Tolueno, Etilbenzeno e Xilenos - BTEX, presentes nesses combustíveis, são extremamente tóxicos à saúde humana e podem inviabilizar a exploração de aqüíferos por eles contaminados e consequentemente os poços utilizados para abastecimento.

$\mathrm{O}$ propósito dos equipamentos e acessórios do SASC, além de dar condições ao empreendimento de armazenar e comercializar combustíveis, é a proteção do meio ambiente. Basicamente são 5 funções que esses equipamentos devem promover (ABNT NBR 13.786, 2005):

1. Proteção contra vazamento;

2. Proteção contra derramamento;

3. Proteção contra transbordamento;

4. Proteção contra corrosão dos tanques;

5. Proteção contra corrosão em tubulações subterrâneas.

Levando-se em consideração o grande número de postos revendedores de combustíveis existentes no Brasil e sua localização, muitas vezes, em regiões intensamente povoadas, é de fundamental importância a realização de avaliações das condições construtivas, de manutenção e de funcionamento dos postos revendedores.

Os Equipamentos a serem instalados deverão seguir as seguintes especificações 
técnicas:

1. A boca de recebimento de produto do tanque deve possuir adaptador de resgate rápido, para que o abastecimento só possa ser feito através do sistema tipo descarga selada, de modo que não seja possível o transbordamento durante o seu abastecimento;

2. Tanque de parede dupla com sensor de monitoramento intersticial;

3. As tubulações ligadas ao tanque devem possuir proteção contra corrosão, idêntica ou compatível com a usada no tanque;

4. A bomba de sucção deve possuir válvula de retenção junto a entrada de produto, alinhando-se sua utilização na extremidade da tubulação no interior do tanque, evitando se assim, que, na falta de estanqueidade de tubo, ou produto vaze para o solo;

5. Possuir sistema de drenagem de águas contaminadas com combustíveis, óleos ou graxas, independente do uso da drenagem pluvial ou de águas servidas. Esse sistema deverá separar a água dos demais contaminantes referidos;

6. Toda instalação elétrica em locais onde possa haver presença de vapores inflamáveis deve atender as normas da ABNT;

7. Todas as tubulações subterrâneas de sucção devem ser do tipo flexível em PEAD (polietileno de alta densidade) classe $10 \mathrm{~kg} / \mathrm{cm} 2$ (1Mpa) com diâmetro 2 " (conforme as normas técnicas da $\mathrm{ABNT}$ ). Já as tubulações aéreas referentes aos respiros dos tanques devem ser em ferro galvanizado conforme norma técnica correspondente;

8. Instalar câmara de contenção da descarga de combustível, câmara de contenção sob a unidade abastecedora, câmara de acesso a boca de visita e câmara de contenção na unidade de filtragem de diesel;

9. O tanque deve possuir uma válvula anti-transbordamento, ou válvula de retenção de esfera flutuante, ou alarme de transbordamento;

10. Instalar, nas bocas dos respiros dos tanques, válvulas anti-chamas, conforme recomendação da NBR 13.784 da ABNT;

11. Todos os equipamentos deverão atender às Normas Técnicas da ABNT, bem como apresentarem certificação do INMETRO ou entidade por ele credenciado;

12. Todas as instalações de equipamentos e testes de estanqueidades deverão atender às Normas Técnicas da ABNT, bem como apresentarem certificação do INMETRO ou entidade por ele credenciado; 
Os vazamentos de combustíveis podem ocorrer pelos seguintes motivos:

- derramamentos superficiais junto às bombas de abastecimento e durante a operação de transferência do produto para o tanque ou abastecimento devido à infiltração nas rachaduras do piso do posto;

- vazamentos na própria bomba de abastecimento, no sistema ou no tanque subterrâneo devido á corrosão;

- Falhas estruturais das tubulações subterrâneas conectadas ao tanque;

- Instalação inadequada.

No Brasil, a atenção para incidentes ambientais com postos de combustíveis começou pelo Estado de São Paulo, através da Central de Atendimento de Emergências Ambientais da CETESB, que teve o seu primeiro caso em 1984. Até 2004, foram registrados 550 casos de emergências de Postos Revendedores no estado de São Paulo (Santos, 2005). A partir desse ano os números de casos cresceram a cada ano até o ano de 1999, quando se iniciou a discussão de uma resolução específica para licenciamento de Postos Revendedores no CONAMA. A partir deste ano, houve uma pressão da CETESB junto aos Postos Revendedores no sentido de providenciarem melhorias das suas instalações com vistas a reduzirem o número de acidentes, bem como o atendimento à Resolução CONAMA n ${ }^{\circ} 273$, que só foi publicaa no Diário Oficial da União no início do ano de 2001.

Em Sander et al (2007), a Resolução CONAMA n ${ }^{\circ} 273$, é considerada uma das mais importantes leis em procedimentos de segurança para estabelecimentos proprietários de tanques subterrâneos de armazenamento de combustíveis.

Souza (2009, p.46) cita que em caso de acidentes ou vazamentos que representem situações de perigo ao meio ambiente ou a pessoas, bem como na ocorrência de passivos ambientais, os proprietários, arrendatários ou responsáveis pelo estabelecimento, pelos equipamentos, pelos sistemas e os fornecedores de combustível que abastecem ou abasteceram a unidade responderão solidariamente, pela adoção de medidas para controle da situação de emergências, e para o saneamento das áreas impactadas, de acordo com as exigências formuladas pelo órgão ambiental licenciador.

Conforme o descrito no artigo $\mathrm{n}^{\circ} 54$ da Lei $\mathrm{n}^{\circ} 9.605$ de 12 de fevereiro de 1998, regulamentada pelo Decreto 3.179/99: 
Art. 54. Causar poluição de qualquer natureza em níveis tais que resultem ou possam resultar em danos à saúde humana, ou que provoquem a mortandade de animais ou a destruição significativa da flora:

Pena - reclusão, de um a quatro anos, e multa.

$\S 1^{\circ}$. Se o crime é culposo: Pena - detenção, de seis meses a um ano, e multa.

$\S 2^{\circ}$. Se o crime:

- Tornar uma área, urbana ou rural, imprópria para a ocupação humana;

- Causar poluição atmosférica que provoque a retirada, ainda que momentânea, dos habitantes das áreas afetadas, ou que cause danos diretos à saúde da população;

- Causar poluição hídrica que torne necessária a interrupção do abastecimento público de água de uma comunidade;

- Dificultar ou impedir o uso público das praias;

- Ocorrer por lançamento de resíduos sólidos, líquidos ou gasosos, ou detritos, óleos ou substâncias oleosas, em desacordo com as exigências estabelecidas em leis ou regulamentos:

Pena - reclusão, de um a cinco anos.

Em caso de acidentes ou vazamentos que apresentem situações de perigo ao meio ambiente ou às pessoas, bem como na ocorrência de passivos ambientais, os proprietários, arrendatários ou responsáveis pelo estabelecimento, equipamentos, sistemas e os fornecedores de combustíveis que abastecem ou abasteceram a unidade, responderão solidariamente pela adoção de medidas para controle da situação emergencial e para o saneamento das áreas impactantes (Resolução do CONAMA N²73/00).

\section{Considerações finais}

A aplicabilidade da legislação ambiental nos postos de combustíveis devem ser efetivadas com urgência. A inexistência de uma gestão ambiental adequada para o setor podem desencadear ações desarticuladas que, além de impedirem o equacionamento dos problemas, 
podem gerar grandes danos ambientais. Recomenda-se com intuito de minimizar esse impacto causado pelos resíduos sólidos nos postos de combustíveis que: os resíduos sejam separados por classe, acondicionem seus resíduos sólidos em tambores adequados e que seja em local impermeabilizado, destinar os óleos usados a empresas licenciadas ambientalmente e elaborar Plano de Gerenciamento de Resíduos Sólidos.

A identificação dos pontos de geração dos resíduos sólidos foi feita in loco em cada setor do posto. Considerando a Resolução CONAMA n $273 / 00$ e com base na Norma ABNT NBR 10.004, na Classificação dos Resíduos Sólidos foram listados os filtros de óleo, as embalagens de óleo lubrificante, areia e lodo do fundo do(s) separador(es), água/óleo e caixas de areia e ainda outros resíduos (administração, restaurante, etc).

Tabela 1 - Levantamento de Resíduos Sólidos gerados no Empreendimento

\begin{tabular}{l|l|l}
\hline Resíduos Sólidos & Classe & Destinação Final \\
\hline $\begin{array}{l}\text { Embalagem de óleo, óleo } \\
\text { lubrificante contaminado, } \\
\text { estopas contaminadas, filtro } \\
\text { contaminado com óleo, areia } \\
\text { da caixa separadora e }\end{array}$ & Classe I & $\begin{array}{l}\text { Coletado por empresa } \\
\text { especializada }\end{array}$ \\
$\begin{array}{ll}\text { lâmpadas fluorescentes. } \\
\text { Lixo orgânico, plástico, papel, } \\
\text { vidro e rejeito sanitário. }\end{array}$ & Classe II & \\
\hline
\end{tabular}

As informações relativas ao transporte e coleta externa dos resíduos sólidos gerados foram prestadas pelo empreendedor. Entre as quais, destacou-se a informação de que a empresa responsável pela coleta e transporte dos resíduos possui licença ambiental para executar tais serviços.

Verificou-se, através da aplicação do questionário, que o posto preocupa-se com as questões ambientais e atende a priori a legislação ambiental. Além de desenvolver práticas ambientais de descarte adequado dos resíduos produzidos, que são encaminhados para empresas evitando assim a degradação do meio ambiente. O óleo proveniente da troca de óleo é coletado pela empresa autorizada pela ANP, o mesmo é armazenado em local coberto com piso impermeável. As estopas contaminadas, filtros e embalagens vazia de óleo lubrificante são 
encaminhadas para serem incinerados por empresa devidamente licenciada, pelo órgão ambiental competente.

Ao analisar a estrutura física do posto, foi possível constatar que o mesmo possui: Possui tubulações exaladoras de gases com válvula anti-chama, o piso da área do abastecimento e dá área de descarga é feito em concreto armado com canaletas interligadas a Caixa separadora de água e óleo, $\mathrm{O}$ armazenamento do combustível é feito através de 03 (três) tanques jaquetados, para atender 04 (quatro) bombas com 08 (oito) bicos, as tubulações subterrâneas de sucção é do tipo flexível e PEAD; Possui câmara de contenção da descarga de combustível, câmara de contenção sob a unidade abastecedora, câmara de contenção na boca de visita e câmara de contenção na unidade de filtragem de diesel. Os produtos comercializados são gasolina, gasolina aditivada, etanol e óleo diesel.

A água proveniente da pista de abastecimento é captada pelas canaletas e em seguida encaminhado para um Sistema Separador de Água e Óleo - SAO, com finalidade de reter algum produto química que venha a ser derramado. Não realiza o serviço de lavagem de veículos.

$\mathrm{O}$ referido posto possui Licença Ambiental vigente, emitida pelo órgão ambiental estadual. O licenciamento ambiental é sem dúvida um processo de grande importância no âmbito da preservação do meio ambiente, pois através dele pode-se fiscalizar e exigir de empreendimentos com potencial de degradação formas de minimizar os impactos ambientais negativos causados por suas atividades.

Com base no exposto pode-se concluir que o desempenho ambiental do posto analisado encontra-se satisfatório quanto aos requisitos ambientais legais analisados. Por fim espera-se que os postos revendedores busquem a melhoria contínua em suas funções de proteção ambiental.

\section{Referências}

ABNT. ASSOCIAÇÃO BRASILEIRA DE NORMAS TÉCNICAS. NBR 10.004 Resíduos sólidos - Classificação. Rio de Janeiro, 2004. Disponível em: $<$ http://www.aslaa.com.br/legislação/NBR\%20n\%2010004-2004.pdf. Acesso em: 8.fev.2015. 
ABNT. ASSOCIAÇÃO BRASILEIRA DE NORMAS TÉCNICAS. NBR $\mathbf{1 0 . 0 0 7}$ Amostragem de resíduos. Rio de Janeiro, 2004. Disponível em:< http://wp.ufpel.edu.br/residuos/files/2014/04/nbr-10007-amostragem-de-rescsc3blido .pdf. Acesso em: 07 de Julho de 2016.

GOMES, PRISCILA LUGGERI et al. Aspectos e impactos no descarte de óleos lubrificantes: o caso das oficinas. IV CONGRESSO NACIONAL DE EXCELÊNCIA EM GESTÃO Responsabilidade Socioambiental das Organizações Brasileiras Niteroi, RJ, Brasil, 31 de julho, 1 e 2 de agosto de 2008. Disponívelem:<http://www.latec.uff.br/cneg/documentos/anais_cneg4/T7_0035_0236.pdf. Acesso em: 07 de Julho de 2016.

Guidoni Rosemeire. A solução é inverter a pirâmide. Disponível em $<$ http://revistacombustiveis.com.br/edicao40/meioambiente02.htm>. Acesso em: 07 de Julho de 2016.

$$
\text { Manual ee Coleta Seletiva disponível }
$$

em: $<$ http//www.fiesp.com.br/publicações/pdf/ambiental/manual_coleta_seletiva.pdf. Acesso: em: 07 de Julho de 2016.

SANTOS, Ricardo José Shamá dos. A gestão ambiental em posto revendedor de combustíveis como instrumento de prevenção de passivos ambientais. 2005. 217f. Dissertação (Mestrado em Sistemas de Gestão do Meio Ambiente) -Universidade Federal Fluminense, Niterói, 2005.

SOUZA, Camila Pinto de. Avaliação e Valoração dos Impactos Ambientais no Processo de Operação de Postos Revendedores de Combustíveis. 2009. 182 f. Dissertação (Mestre em Ciências) - Curso de Pós-graduação em Tecnologia de Processos Químicos e Bioquímicos, Universidade Federal do Rio de Janeiro, Rio de Janeiro, 2009. Disponível em: <http://www.eq.ufrj.br/sipeq/download/impactos-ambientais-dos-postos-de-combustivel.pdf $>$. Acesso em: 07 de Julho de 2016.

PHILIPPI Jr., Arlindo(editor). Saneamento, Saúde e Ambiente: Fundamentos para um desenvolvimento sustentável. Barueri: Manole, 2000. 842p.

POLITICA NACIONAL DO MEIO AMBIENTE. Lei $\mathbf{n}^{\mathbf{0}} \mathbf{6 . 9 3 8}$, de 31 de agosto de 1981. Brasília, 1981. Disponível em: <http//www.planalto.gov.br/ccivil_03/leis/L6938.htm. Acesso em: 07 de Julho de 2016.

LEI DE CRIMES AMBIENTAIS. Lei no 9.605, de 12 de Fevereiro de 1998. Brasília, 1998. Disponível em: <http://www.planalto.gov.br/ccivil_03/leis/L9605.htm Acesso em: 07 de Julho de 2016. 
LEI No 12.621 de 26 de Agosto de 1996. Ceará, 1996. Disponível em: <http://www.semace.ce.gov.br/institucional/procuradoria-juridica/legislacao/. Acesso em: 07 de Julho de 2016.

PROGRAMA piloto para a minimização dos impactos gerados por resíduos perigosos: gestão de óleo lubrificante automotivo usado - estado de Pernambuco. Ministério do Meio Ambiente. Brasília: MMA, 2007. 40p.

CONSELHO NACIONAL DO MEIO AMBIENTE - CONAMA. Resolução nº $\mathbf{0 5}$, de 05 de agosto de 1993. Dispõe sobre os procedimentos mínimos para o gerenciamento de resíduos com vistas a preservar à saúde... Disponível em: http://www.mma.gov.br/port/conama/res/res93/res0593.html. Acesso em: 07 de Julho de 2016.

CONSELHO NACIONAL DO MEIO AMBIENTE - CONAMA. Resolução no $\mathbf{n}^{\mathbf{0 1}}$, de 23 de janeiro de 1986. Dispõe sobre critérios básicos e diretrizes gerais para o Relatório de Impacto Ambiental - $\quad$ RIMA. Disponível em: http://www.mma.gov.br/port/conama/legiabre.cfm?codlegi=23. Acesso em: 07 de julho de 2016.

CONSELHO NACIONAL DO MEIO AMBIENTE - CONAMA. Resolução n $\mathbf{2 7 3}$, de 29 de Novembro de 2000. Estabelece diretrizes para o licenciamento ambiental de postos de combustíveis e serviços e dispõe sobre a preven-ção e controle da poluição...Disponível em: http://www.mma.gov.br/port/conama/legiabre.cfm?codlegi=271, Acesso em: 07 de Julho de 2016.

CONSELHO NACIONAL DO MEIO AMBIENTE - CONAMA. Resolução no 237, de 19 de dezembro de 1993. Dispõe sobre o licenciamento ambiental; competências da União, Estados e Municípios; listagem de atividades... Disponível em: http://www.mma.gov.br/port/conama/legiabre.cfm?codlegi=237. Acesso em: 14 fev. 2015.

VALLE, C.E. Como sepreparar para as normas ISO14000 Qualidade Anlbiental-O Desafio de Ser Competitivo Protegendo o Meio Ambiente. 3 ed. São Paulo: Pioneira Administração e Negócios, 2000.

Como citar este artigo (Formato ABNT):

LIMA, Fernanda F.S.; NASCIMENTO, Maria Cristina D.; FARIAS, Athena de A. Aplicabilidade da Legislação Ambiental em um Posto de Combustíveis em Juazeiro do Norte/Ceará . Id on Line Revista Multidisciplinar e de Psicologia, Maio de 2017, vol.11, n.35, p.227-253. ISSN: 1981-1179.

Recebido: 19.05.2017

Aceito: 24.05 .2017 